\title{
A ATUALIDADE DO LIVRO HISTÓRIA DO MENINO QUE LIA O MUNDO NO ANO DO CENTENÁRIO DE PAULO FREIRE
}

TOPICALITY FROM THE BOOK HISTÓRIA DO MENINO QUE LIA O MUNDO IN THE YEAR OF THE CENTENNIAL OF PAULO FREIRE

https://orcid.org/0000-0001-5965-7953 Rafaela Domingues Pereira $1^{\text {iA }}$

${ }^{\text {A }}$ Universidade Federal do Rio de Janeiro (UFRJ), Rio de Janeiro, RJ, Brasil

Recebido em: 30042021 | Aceito em: 22062021 Correspondência: Rafaela (rafaeladomingues@ufrj.br)

BRANDÃO, Carlos Rodrigues. História do menino que lia o mundo. São Paulo: Editora Expressão Popular, 2014.

O livro infanto-juvenil História do menino que lia o mundo (2014), escrito por Carlos Rodrigues Brandão, enfrenta a importante tarefa de contar a trajetória de Paulo Reglus Neves Freire (1921 - 1997) para crianças, para jovens e - por que não? - para os já adultos. A maior parte da produção acadêmica sobre Paulo Freire já dá destaque aos ineditismos inaugurados pela Teoria do Conhecimento formulada pelo Patrono da Educação Brasileira, que é também, na atualidade, o terceiro teórico mais citado em trabalhos acadêmicos na área das Ciências Humanas no mundo todo ${ }^{\mathrm{ii}}$. Contudo, o livro de Brandão é a primeira obra com a pretensão de narrar a trajetória de vida de Paulo Freire e apresentar as bases de seu pensamento ao público infanto-juvenil.

Brandão é um reconhecido pesquisador brasileiro, possui ampla produção nas áreas da Antropologia e da Educação, estando a maior parte de sua obra disponível para download gratuito em seu site oficial: https://apartilhadavida.com.br/. Após graduar-se em Psicologia pela Pontifícia Universidade Católica do Rio de Janeiro (PUC-RJ), realizou seu mestrado em Antropologia pela Universidade de Brasília $(\mathrm{UnB})$ e o doutorado em Ciências Sociais pela Universidade de São Paulo (USP). Atuou como professor livre-docente na Universidade Estadual de Campinas (Unicamp). Atualmente é professor colaborador do Mestrado em Tradições Culturais do Cerrado, da Universidade Estadual de Goiás (UEG). 
De acordo com o próprio (BRANDÃO, 2017), sua trajetória foi significativamente marcada por Paulo Freire, com quem conviveu intensamente no período em que o educador regressou ao país após o exílio. Além de militante junto aos movimentos sociais, Brandão é um dos pesquisadores de referência no estudo da Educação Popular e do pensamento freiriano no Brasil. No campo da literatura infantil, para além da obra que resenhamos aqui, escreveu livros de contos e de poesias para crianças, entre eles Semente: Poemas para crianças pensarem o meio ambiente (2000) e Furundum: Canções e cores de carinho com a vida (2001).

O livro História do menino que lia o mundo foi publicado em 2014, mas seu texto foi redigido, pouco tempo após o falecimento de Freire, em virtude de um pedido do Movimento dos Trabalhadores Rurais Sem Terra (MST) a Brandão. Inicialmente, a obra foi editada pelo próprio MST, sendo publicada no Caderno ${ }^{\circ} 7$ da Coleção Fazendo História, que é uma coleção de materiais didáticos voltados para o Ensino de História nas ações educativas do MST.

Em 2005, o texto de Brandão foi ampliado e publicado pela Editora Unesp, sob o título de Paulo Freire, o menino que lia o mundo: uma história de pessoas, de letras e de palavras. Essa versão trouxe contribuições de Ana Maria Araújo Freire, viúva do educador e sua sucessora legal. Por fim, a versão originalmente escrita para o MST foi publicada em 2014 pela Editora Expressão Popular.

História do menino que lia o mundo apresenta uma linguagem acessível e de fácil leitura para todas as idades. O prefácio foi escrito por Miguel Gonzalez Arroyo, sociólogo e professor emérito da Universidade Federal de Minas Gerais (UFMG). Nesse texto introdutório, é possível notar a tentativa de aproximar a história de Freire à trajetória dos leitores, sobretudo no caso das crianças do campo, público para o qual a obra originalmente se destina. Há a preocupação de incentivar os leitores a contar suas próprias histórias, tal como salienta Arroyo no prefácio:

\footnotetext{
Este livro conta a História do menino que lia o mundo. O menino que cresceu, virou jovem, adulto, professor. Resolveu contar a sua história. E você, já teve vontade de escrever sua história? Lembra? (...) Todos nós tivemos uma professora que pediu para fazer uma redação contando a nossa história. (...) A história de Paulo Freire, o menino que lia o mundo se parece com a nossa. Como ele, nós temos vontade de ler as letras, sobretudo vontade de ler os significados de nossa vida, nossa família, do trabalho no campo. (...) A História do menino que lia o mundo é a história de tantos meninos e meninas do campo que também querem ler o mundo. Uma história que não terminou porque há no campo crianças, jovens, famílias, professoras/professores que continuam essa história cada vez que aprendem a ler a cartilha e o livro. Cada vez que aprendem a se deixarem interrogar pela terra e pelo mundo. Vamos ler esta História do menino que lia o mundo para ter mais vontade de contar nossa história no campo. Mais vontade de ler o mundo (ARROYO, 2014, p.7. Grifos do autor).
}

Além da apresentação de Arroyo, o livro é composto por seis capítulos e mais a conclusão. Os primeiros quatro capítulos apresentam a trajetória de vida de Freire e aspectos 
de seu pensamento educacional. Sendo que os dois primeiros, intitulados $O$ menino da sombra das mangueiras e Do Recife para Jaboatão, narram sua infância. Nesses capítulos iniciais, a partir das memórias narradas por Freire em suas obras, Brandão descreve como o menino Paulo teria aprendido a ler as palavras e, também, a "ler o mundo". Ao mesmo tempo, o autor destaca pontos centrais do pensamento freiriano, dentre eles a ideia de que homens e mulheres aprendem se relacionando com o mundo e com os outros, como pode-se observar na passagem abaixo:

Quando a gente vai para a escola, alguns alunos dizem: "vai estudar pra ver se você aprende alguma coisa! Não é mesmo? Mas eles esquecem que, quando uma criança chega na escola, ela já aprendeu muito e muito. Aprendeu com um mundo. Aprendeu de olhar, tocar e ver o mundo onde ela vive. Aprendeu com os outros: a mãe e o pai, os irmãos e as irmãs mais velhos, os primos e os outros parentes. Aprendeu com as amigas e os amigos da mesma idade. Aprendeu com a vida. Pois a vida que a gente vai vivendo, um pouquinho cada dia, é a melhor professora de cada uma e de cada uma de nós. (...) Vejam vocês, quando a gente chega na escola e é o primeiro dia de aula, já aprendeu tanta coisa! Já aprendeu a subir nos galhos da mangueira e a saber qual é a diferença entre um gato e um galo. Já aprendeu a conviver com pai-e-mãe, com os irmãos e as primas. Já aprendeu a falar e já aprendeu e entender uma língua chamada "o português", que depois a gente vai estudar para aprender a ler e escrever com as professoras na escola. Não é assim? (BRANDÃO, 2014, p. 17).

"Na escola", continua Brandão, "aprendemos os números e as contas da matemática, e as letras, as palavras e as frases do português (...) mas, antes da ESCOLA, a VIDA ensina o escuro e o claro, o alto e o baixo, o frio e o quente, o grande e o pequeno" (BRANDÃO, 2014, p. 19. Grifos do autor).

No terceiro capítulo, intitulado De menino a gente grande, de estudante a professor, o percurso formativo de Freire como educador é apresentado aos leitores. Desde seu ingresso na Faculdade de Direito do Recife, passando pelo trabalho realizado na direção do Serviço Social da Indústria (Sesi), em que Freire teve contato com a Educação de Jovens e Adultos, até sua participação no Movimento de Cultura Popular nos anos sessenta. Brandão destaca que Freire começava a entender que

uma coisa é falar como quem só fala, pensando que sabe tudo. Pensando que sabe tudo e dizendo o que pensa que sabe só para as outras pessoas ouvirem e pensarem que aprendem. E outra coisa é saber falar ouvindo os outros. Falar como quem primeira escuta. Como quem aprende primeiro, antes de dizer o que sabe... antes de ensinar. Paulo Freire foi aprendendo o que depois começou a ensinar a toda a gente: quem ensina como um professor primeiro aprende a aprender com outros professores e também com os seus alunos (BRANDÃO, 2014, p. 35).

A partir dessa proposta de aprendizagem política e epistemológica, Freire e os demais militantes da Educação Popular viviam questionando e perguntando para si e para os outros:

Se tudo o que existe de bom no Mundo deveria ser repartido entre todas as pessoas do Mundo, por que é que algumas pessoas têm tantas coisas e as outras têm tão pouco? Se há tanta terra para plantar e para viver nesse "mundão sem fim", porque é que tem Revista Interinstitucional Artes de Educar. Rio de Janeiro, V.7, N.2- p. 1337-1344 mai-ago de 2021: "Dossiê História das Mulheres e Educação”- DOI: 10.12957/riae.2021.63476 
gente que tem muito mais terra do que precisa, enquanto tantas outras pessoas e tantas famílias não têm terra nenhuma? (...) por que tantas e tantas pessoas trabalham tanto e ganham tão pouco, enquanto outras trabalham tão pouco e ganham muito? Se todas as pessoas - das criancinhas aos velhinhos - nasceram para serem livres e felizes toda a vida, por que que é que tantas pessoas não podem fazer o que querem? Por que é que elas não podem viver como elas sonham? Porque é que elas não podem ser livres como os sabiás fora da gaiola e felizes como o menino Paulo foi, no alto das mangueiras do quintal da casa do Recife? (BRANDÃO, 2014, p. 38).

Todos esses questionamentos estavam relacionados com sua defesa de uma vida pautada no amor e na justiça,

onde todas as pessoas possam conviver partilhando entre elas tudo o que é bom no nosso MUNDO. Todos os bens da TERRA, da VIDA e do TRABALHO. Uma vida de milho e feijão crescendo no chão molhada de dezembro, numa terra arada e cuidada pelas mãos de toda a gente. Com semente jogada numa terra de todos, e onde a colheita dos frutos vai ser também distribuída entre todos, sem que alguns poucos fiquem com tanto e tantas outras pessoas que trabalharam tanto fiquem com tão pouco. Por que não sonhar com um MUNDO assim? Por que não trabalharmos juntos para que o nosso MUNDO seja assim? E era com o sonho neste MUNDO que tudo se fazia nos “movimentos de cultura popular". (BRANDÃO, 2014, p. 38. Grifos do autor).

No quarto capítulo, De Angicos para muito longe, Brandão apresenta a disseminação das ações da Educação Popular nos anos sessenta e a pretensão do Plano Nacional de Alfabetização, do Governo de João Goulart, de utilizar o "Método Paulo Freire de Alfabetização" por todo o país. O autor salienta que, até então,

todo o material que havia para ensinar as pessoas adultas a ler e a escrever estava escrito e desenhado para ensinar das crianças. E foi por isso que Paulo Freire e a sua equipe de educadores começaram a pensar um jeito diferente de ensinar as pessoas a escrever e a ler em português (...) um "método" de alfabetizar gente grande (BRANDÃO, 2014, p. 39).

Além disso, Brandão chama atenção para a efetividade e para a agilidade com que tal método possibilitava o ensino de adultos. De acordo com o autor,

as pessoas aprendiam a ler e a escrever mais depressa e bem melhor. Porque elas não aprendiam só a ler e escrever as palavras, mas elas aprendiam a escrever e ler pensando, refletindo. Ah! Agora elas podiam aprender a ler palavras aprendendo a pensarem cada vez mais com a própria cabeça. Aprenderem a ler aquilo que já sabiam falar! E isso é uma das coisas mais importantes da vida, vocês não acham? (BRANDÃO, 2014, p. 41).

Em seguida, Brandão descreve as desconfianças de alguns grupos e setores da sociedade em relação a essa forma de ensino-aprendizagem, assinalando que

tinha gente que achava o "Método Paulo Freire" e todas as ideias dele um perigo. Vejam só! E por que é que achavam "um perigo" o que o professor Paulo tinha inventado? Porque ele e a sua equipe eram professores e eram professoras muito preocupadas com tudo o que eles viam acontecer à sua volta. Havia tanta pobreza por toda a parte! Tanta desigualdade entre as pessoas de um mesmo povoado, de uma mesma cidade, como Angicos, de um mesmo Pernambuco, dentro de um mesmo Brasil e em todo o Mundo! (BRANDÃO, 2014, p. 41). 
A partir da instauração da Ditadura Militar, os Movimentos de Educação Popular tiveram sua existência proibida no Brasil e o Método Paulo Freire não pôde mais ser utilizado. Diante desse cenário, devido à perseguição sofrida, Paulo Freire partiu para o exílio. As tentativas por parte do Regime de coibir ações da Educação Popular se baseavam na ideia de que era "perigoso" educar os pobres. Nas palavras de Brandão (2014),

as pessoas que achavam que era muito perigoso educar as mulheres e os homens pobres do campo e da cidade proibiram os professores de trabalharem com a EDUCAÇÃO POPULAR. Eles não queriam mesmo gente ensinando as mulheres e os homens pobres do campo e da cidade a pensarem com as suas próprias cabeças. Não queriam ver os lavradores e os operários pensando juntos, "lendo" o mundo em que eles viviam e se unindo para fazer alguma coisa. Unindo cabeças e corações para dar um jeito de mudar o Brasil em um País justo e feliz. E assim proibiram qualquer tipo de trabalho com esse nome: EDUCAÇÃO POPULAR. Foi quando ficou proibido em todo o Brasil alfabetizar pessoas usando o "Método Paulo Freire". Foi um tempo muito triste aquele tempo! Muita gente foi presa em muitos lugares do Brasil e isto aconteceu também com o professor Paulo. Ele foi preso e depois precisou ir embora para bem longe daqui. Junto com a mulher dele, a Elza, e junto com filhas e filhos, ele viajou para outros países e passou mais de 15 anos longe do Recife, longe de Pernambuco e longe do Brasil que ele amava tanto (BRAND ̃̃O, 2014, p. 43. Grifos do autor).

Os caminhos percorridos durante o exílio de Freire foram da Bolívia ao Chile, dos Estados Unidos à Suíça e da Europa aos países africanos de Angola, Moçambique e Cabo Verde. Nesse período, o "Método Paulo Freire" se espalhou por todo o mundo: "Vejam vocês, um professor proibido de voltar na sua terra e querido e procurado por pessoas de todo o mundo" (BRANDÃO, 2014, p. 46). Narrando a volta do educador ao país, em 1979, o quarto capítulo se encerra. Assim, é rememorada a passagem de Freire como Secretário da Educação da cidade de São Paulo (1989 - 1991), o falecimento de sua companheira Elza em 1986, o casamento com Ana Maria Araújo no ano de 1988 e o falecimento de Freire em 1997.

Os dois últimos capítulos - Pensando e vivendo, aprendendo e ensinando e Jogo das palavras-sementes - propõem uma atividade para que as crianças possam aprender na prática, por meio de um jogo, o chamado Método Paulo Freire. A sugestão é que a atividade seja realizada pelas crianças com a ajuda de professores ou mesmo só entre elas. No caso de convidarem os professores, Brandão sugere que "digam para eles que, 'na roda do jogo', todo mundo é igual e ensina aprendendo e aprende ensinando" (BRANDÃO, 2014, p. 53).

O jogo das "palavras-sementes" é dividido em quatro etapas, nomeadas respectivamente de "Começa assim", "Vai indo assim", "Continua assim" e "Acaba assim". A primeira etapa consiste no levantamento daquilo que Freire designava por "universo vocabular" da população que seria alfabetizada. Na versão para crianças, o levantamento do "universo vocabular" é 
denominado "levantamento das palavras-sementes". A orientação dada é que as crianças prestem atenção nas palavras que utilizam enquanto conversam. A seguir, devem escrever as palavras mais faladas em uma lista e, depois, escrever cada uma delas em uma ficha, formando assim as "fichas das palavras-sementes".

Na segunda etapa, as fichas devem ser embaralhadas e cada participante deve pegar uma ficha. A partir da palavra escolhida, deve-se pegar uma ficha em branco e decompor as palavras em sílabas, alternando as vogais na sequência do A-E-I-O-U. Por exemplo, no caso da palavra "maravilha", a nova ficha criada deve ficar assim: Ma-ra-va-lha; Me-re-ve-lhe; Mi-ri-vi-lhi; Mo-ro-vo-lho; Mu-ru-vu-lhu. Cada ficha produzida nesse momento será uma "ficha jardineiro".

Na etapa seguinte, a tarefa é combinar as sílabas - as sementes - que foram escritas para formar novas palavras. Segundo Brandão (2014, p. 59) é “olhar para as sílabas de cada Ficha de Jardineiro e ir formando palavras. O tamanho delas nem importa. Pode ser palavra de duas letras". Inclusive, podem ser palavras que nem existem: "Professor tem mania de implicar com palavra que não existe. Com palavra que eles acham que a gente fala errado. Mas, nesse jogo (...) pode inventar o que quiser (...) desde que fique bonito e inteligente" (Brandão, 2014, p. 59). O desfecho da brincadeira consiste em juntar as palavras construídas para formar um poema, uma história ou uma mensagem.

Finalizada essa breve exposição acerca da estrutura do livro, não podemos deixar de registrar a escalada da perseguição contra Paulo Freire e seu pensamento no Brasil. No mesmo ano de lançamento do livro de Brandão para o grande público, em 2014, foi criado o movimento Escola Sem Partido (ESP), o qual alinhando-se a grupos conservadores, ganharia visibilidade nos anos posteriores ao acusar professores de "doutrinação ideológica", atacando o legado de Paulo Freire, transformando-o em símbolo de uma suposta doutrinação marxista e comunista realizada nas escolas do país. Para o ESP, a perspectiva freiriana deveria ser rechaçada na esfera política e pedagógica, pois, segundo declaração de Miguel Nagib, coordenador e advogado do movimento,

alguns dos ensinamentos de Paulo Freire se chocam com a Constituição. Nossa crítica é de natureza jurídica, porque o uso da sala de aula para efeito de transformação da sociedade, como ele defendia, dependendo da maneira com que isso é aplicado, viola a liberdade dos alunos e a neutralidade política e ideológica do Estado (Revista Galileu, 2017) ${ }^{\text {iii. }}$

A aversão do movimento à pedagogia do educador pode, em parte, ser compreendida pelo fato de o projeto defendido pelo ESP ir contra aspectos fundantes da teoria freiriana. Enquanto o ESP naturaliza a realidade social e suas desigualdades ao defender uma pretensa neutralidade dos professores no processo de ensino-aprendizagem, Freire defendia, ao 
contrário, que as desigualdades sociais não são naturais, afirmando que "o mundo não é, o mundo está sendo" e que

não existe educação neutra, toda neutralidade afirmada é uma opção escondida", pois "a qualidade de ser política, inerente à sua natureza. É impossível, na verdade, a neutralidade da educação. E é impossível, não porque professoras e professores "baderneiros e subversivos" o determinem. A educação não vira política por causa da decisão deste ou daquele educador. Ela é política (FREIRE, 1996, p. 56).

Após as eleições brasileiras de 2018, com a ascensão de grupos de direita aos poderes Executivo e Legislativo, os ataques ao legado de Freire ganharam ainda mais força. Já durante sua campanha eleitoral, o atual presidente defendia a erradicação da "ideologia de Paulo Freire" das escolas ${ }^{\text {iv }}$. Ademais, a perseguição a Freire tornou-se recorrente em seu mandato, especialmente em declarações de representantes do Governo Federal. O ex-ministro da Educação Abraham Weintraub, por exemplo, em seu discurso de posse, levantou o seguinte questionamento: "se temos uma filosofia de educação tão boa, Paulo Freire é uma unanimidade, por que temos resultados tão ruins?" Weintraub também declarou em suas redes sociais que o educador "representa o fracasso da educação esquerdista" e que "um dia, o Brasil terá outro patrono da educação!” v.

Em meio ao vigente cenário de retrocessos na área educacional, a atualidade de História do menino que lia o mundo é inegável. A obra é bem-sucedida ao apresentar a trajetória de Paulo Freire, sublinhando a relevância do seu pensamento para as práticas educativas com crianças e adolescentes. Mas, também, por materializar os princípios basilares da pedagogia freiriana, como o respeito aos saberes dos educandos e a preocupação de partir da realidade do público ao qual se dirige no processo de ensino-aprendizagem (nesse caso, o infanto-juvenil). Deste modo, neste ano de 2021 em que comemoramos o centenário de nascimento de Paulo Freire, a obra de Carlos Rodrigues Brandão é um interessante convite para refletir sobre o potencial do pensamento freiriano em práticas educativas voltadas para crianças e jovens, tanto na escola quanto para além dela.

\section{REFERÊNCIAS}

ARROYO, M. G. Prefácio. In: BRANDAO, Carlos Rodrigues. História do menino que lia o mundo. São Paulo: Editora Expressão Popular, 2014.

BRANDAO, C. R. Semente: Poemas para crianças pensarem o meio ambiente. (Coleção Fazendo História nº 06). São Paulo: MST, 2000. 
BRANDAO, C. R. Furundum: Canções e cores de carinho com a vida. Campinas: Autores Associados, 2001.

BRANDAO, C. R. Paulo Freire, o menino que lia o mundo: Uma história de pessoas, de letras e de palavras. São Paulo: Editora da UNESP, 2005.

BRANDAO, C. R. História do menino que lia o mundo. São Paulo: Editora Expressão Popular, 2014.

BRANDÃO, C. R. In: FERNANDES, A.; SPIGOLON, N.; ALVARENGA, M. Entre árvores e sabiás, memórias de Paulo Freire -Conversa com Carlos Rodrigues Brandão. E-mosaicos, v. 6, p. 5-22, 2017.

FREIRE, P. Pedagogia da Autonomia. São Paulo: Paz e Terra, 1996.

\title{
NOTAS
}

\begin{abstract}
' Mestranda do Programa de Pós-graduação em Educação da Universidade Federal do Rio de Janeiro (PPGEUFRJ), vinculada à linha História, Sujeitos e Processos Educacionais e bolsista do Programa de Excelência Acadêmica da Coordenação de Aperfeiçoamento de Pessoal de Nível Superior (CAPES). Cursa MBA em Gestão Escolar na Universidade de São Paulo (USP) e possui especialização em Tecnologias e Educação a Distância pela Faculdade São Luís. É bacharel e licenciada em História pela Universidade Federal do Rio de Janeiro. Desde a graduação desenvolve pesquisas nas áreas de História do Brasil e de História da Educação. Atualmente, no mestrado, estuda a criminalização da Pedagogia Freiriana na Ditadura Militar. Currículo Lattes: http://lattes.cnpq.br/2791056258358621.

ii Segundo pesquisa realizada por Elliott Green, professor da Escola de Economia e Ciência Política de Londres, o livro Pedagogia do Oprimido de Freire é a terceira obra mais citada mundialmente na área de humanas, contabilizando 72.359 citações, ficando somente atrás de Thomas Kuhn (81.311) e Everett Rogers (72.782), mas mesmo assim a frente de teóricos como Michael Foucault (60.700), Clifford Geertz (48.984) e Karl Marx (40.237). Para mais detalhes, acessar: https://aventurasnahistoria.uol.com.br/noticias/reportagem/historia-quem-foi-paulofreire.phtml. Acesso em 10/04/2021.

iii Disponível em: https://revistagalileu.globo.com/Revista/noticia/2017/05/legado-de-paulo-freire-e-defendidopor-uns-e-odiado-por-outros.html. Acesso em 20/04/2021.

iv Plano de Governo da chapa "Brasil acima de tudo. Deus acima de todos". Disponível em:

http://divulgacandcontas.tse.jus.br/candidaturas/oficial/2018/BR/BR/2022802018/280000614517/proposta_1534 284632231.pdf. Acesso em 27/04/2021.

v Weintraub ameaça tirar mural de Paulo Freire do MEC: "Fracasso da educação". https://educacao.uol.com.br/noticias/2020/05/07/weintraub-ameaca-tirar-mural-de-paulo-freire-do-mec-fracassoda-educacao.htm. Acesso em 27/04/2021.
\end{abstract}

